\title{
DOM CASMURRO E A IRONIA DA FORMAÇÃO
}

Marcelo Brandão Mattos

Recebido 04, fev. 2010 / Aprovado 29, abr. 2010

\section{Resumo:}

A partir dos conceitos bakhtinianos de análise da forma romanesca, sobretudo quanto ao discurso polifônico, o artigo propõe uma leitura do livro de Machado de Assis como um romance de formação, que se vale da ironia para refratar a voz ficcional construída (ou formada) em relação a outras vozes que a pudessem questionar ou desconstruir.

Palavras-chave: Dom Casmurro. Ironia. Romance de formação. Dialogismo e Polifonia. 
Os livros de Machado de Assis, amplamente discutidos pela teoria literária e apreciados pelos chamados leitores maduros, permitem voos analíticos mais altos do que se pode alcançar com boa parte da produção literária nacional, quiçá com o que se produz e já se produziu mundialmente. A riqueza do trabalho machadiano ultrapassa os limites da valorização estética ou da original elaboração de um bom enredo a ser narrado, para atingir os altos níveis da composição autoral e suas possibilidades orquestrais. A leitura dos romances e contos do mestre da literatura nacional requer um olhar atento tanto ao que "se passa na tela" de suas produções quanto à engrenagem que bobina o "filme principal", sem falar - obviamente - de seu engenheiro, engenhoso criador.

Nesse sentido, é-nos natural a escolha de um dos romances do autor como rico suporte para a discussão de certos conceitos teóricos, propostos sobretudo por Mikhail Bakhtin, que tratam das configurações romanescas enquanto conscientes escolhas autorais. Propomos, neste trabalho, uma leitura de Dom Casmurro como um romance de formação, no qual está em jogo a composição de um discurso refratado - ou refratário - elaborado segundo o princípio da ironia lukacsiana, que permite a divisão semântica entre o dizer e o querer dizer. Os conceitos teóricos, norteadores do trabalho, seguirão aqui o curso das idéias do romance, de modo que serão discutidos na medida em que forem suscitados segundo a linearidade atribuída por Machado para contar a história de Bentinho e Capitu. Será ela, com a licença de algumas digressões, a nossa condutora de idéias. Abramos, portanto, a obra-prima machadiana.

As primeiras palavras do romance são a senha para se desvendar uma mensagem autoral que "dorme na sombra de um livro raro". Logo nos dois primeiros capítulos, Do Título e Do Livro, já nos encontramos - nós, leitores - diante de uma duplicidade autoral que guarda a essência das idéias impressas na obra. O autor primário, utilizando-nos da terminologia bakhtiniana para denominar o autor real, "individualidade ativa" da criação (Bakhtin, 2003, p. 180), produz um autor ficcional, o autor secundário, "individualidade vista e enformada" (Ibid., p.180), que assume a enunciação do texto. A autoria compartilhada entre criador e criatura se projetará no nível do discurso, na medida em que - veremos depois - também haverá um subliminar discurso do autor principal encoberto pelo aparente discurso do autor secundário e, entre os dois, uma dissonância ou, nas palavras de Bakhtin, uma refração.

O enunciador do romance se apresenta como autor de um livro de memórias, uma ficcional autobiografia. O velho Bento registra os momentos que marcaram a sua vida e, justificando "os motivos que lhe põem a pena na mão", afirma um desejo de "atar as duas pontas da vida, e restaurar na velhice a adoles- 
cência" para "recompor o que foi" (Cap. II). Estão inscritos, na narrativa, os sinais caracterizadores daquilo que a teoria literária - e mais uma vez citamos Bakhtin - define como romance de formação. O teórico russo observa que, nesse tipo de romance, "a vida do herói e seu caráter se tornam de uma grandeza variável" (BAKHTIN, 2003, p. 235), ou seja, a sua imagem futura é condicionada pelas experiências pelas quais passou e por valores assimilados que ajudaram a construí-lo como sujeito. A teoria bakhtiniana propõe uma divisão desse tipo de romance em cinco categorias que, a nós, não nos convém deter além da consideração de que, embora este romance (aqui aberto) seja tipicamente biográfico - terceira categoria proposta por Bakhtin -, não se pode desconsiderar o seu componente histórico, sugerido na quinta categoria bakhtiniana (que o teórico considera a mais importante), na qual "O homem se forma ao mesmo tempo que o mundo, reflete em si mesmo a formação história do mundo." (ibid., p. 239-240) O sujeito psicologizado criado por Machado de Assis, em busca de um sentido mnemônico para a sua auto-imagem "presente", condicionado pelas vozes que acompanharam o seu processo de formação, "abandonado" por um autor primário que não endossa seu ponto de vista, é um homem de um tempo em que já se pensa a subjetividade como algo múltiplo, conceito historicamente datado, que contextualiza a produção e a "encenação" da obra.

O texto ficticiamente autobiográfico recompõe a história de Bentinho a partir da infância. Ficam registrados os seus sentimentos diante de uma mãe de firmes decisões, a morte de seu pai, a convivência em uma casa de tios, o encantamento com a jovem Capitu, o ingresso no seminário, a amizade com Escobar. Mais tarde, serão narrados a saída do seminário, o casamento com Capitu, as suspeitas da traição da esposa com seu melhor amigo, o nascimento do filho Ezequiel, as crises do casamento, a separação, as mortes de amigos e familiares, e lhe restará a solidão que o acompanhará até a velhice, tempo da "escrita" do livro. O caráter formador do romance é, no plano do discurso ficcional, parte do projeto narrativo de Bento. Quando afirma desejar "atar as duas pontas da vida, e restaurar na velhice a adolescência", o segundo autor declara o seu objetivo de comprovar que "o homem que se tornou" é resultado das agruras pelas quais passou durante a vida. Há uma função argumentativa na seleção de circunstâncias que sustentam, na ficção, a defesa (ou autodefesa) de uma conduta individual no "presente" da narração - ponto em que Bentinho narra os tempos de ação. É a cena de um discurso de autor. Um discurso que simula, portanto, um tom

As citações do romance, por sua notoriedade e sua vasta publicação em diferentes edições, estão assinaladas apenas com o capítulo referido. monológico, tessitura de uma única mão. Um discurso no qual

A voz do heroi sobre si mesmo e o mundo é tão plena como a palavra comum do autor; não está subordinada à imagem objetificada do heroi como uma de suas características mas 
tampouco serve de intérprete para o autor. Ela possui independência excepcional na estrutura da obra, é como se soasse ao lado da palavra do autor, coadunando-se de modo especial com ela e com as vozes plenivalentes de outros herois. (BAKHTIN, 2008, p 5)

Nas entrelinhas do texto, contudo, revelar-se-á um subreptício jogo polifônico que compõe todo discurso individual. As pistas da polifonia que circunda o "monológico"1 discurso de Bentinho estão dispersas em toda a obra, cuidadosamente deixadas por Machado de Assis. Já no primeiro capítulo, não se deve ignorar a informação de que o título do livro de Bento foi criado por um "rapaz do bairro" que o encontrou no trem e, considerando-o indelicado, "acabou alcunhando-o Dom Casmurro" (Cap.I). Em seguida, seus "hábitos reclusos e calados deram curso à alcunha, que afinal pegou." A contribuição do passageiro do trem para o livro (e para a auto-imagem de Bento) pode parecer insignificante, mas marca a presença de um olhar de "outro" - dentre tantos - como definidor dos sentidos contidos em um texto tecido pelas mãos (e pelos olhos) de um só sujeito. Ao fim do capítulo, um desfecho aforístico confirma a idéia de que há uma parceria criativa na obra. Pensando sobre a participação do "poeta do trem" no texto escrito, os autores - o secundário e, com ele, o primário - concluem: "[...] sendo o título seu, poderá cuidar que a obra é sua. Há livros que apenas terão isso dos seus autores; alguns nem tanto" (grifo nosso). A lúdica seleção, feita pelo autor Bentinho, de um título sugerido por outro para a sua biografia é a primeira senha, do autor Machado, para que seja desvendado pelo leitor o mundo polifônico circundante.

Nos capítulos seguintes, Bentinho passa a relatar os seus dias de juventude, começando sua "evocação por uma célebre tarde de novembro" (Cap. II) em que sua família conversava sobre a promessa materna de que ele fosse para o seminário e a perigosa proximidade entre ele e a menina Capitu. São as primeiras vozes a ecoar no "monológico" discurso enunciado por Bento. As últimas aspas são mesmo irônicas e a ironia não é nossa, mas do próprio autor. Machado cria a cena ilusionista:

1 O conceito bakhtiniano de monologia é, aqui e ao longo deste artigo, tomado com a impropriedade necessária ao jogo autoral de esconder as vozes que disputam a autoria do texto bentiniano, o que justifica as aspas empregadas. O discurso machadiano em nada se refere ao que o teórico denomina por monológico, mas simula tal estrutura como estratégia narrativa de enunciação e criação de uma "voz autoral ficcional". um homem solitário (re)constrói o texto da sua vida e, por mais que tenha autenticidade em suas idéias, elas no fundo vão relevar outras vozes precedentes que sustentam esse discurso unicista. É uma irônica expressão da polifonia, própria de um autor que, embora conectado a uma modernidade por vir, sabia onde estava e para quem estava falando. Se a Dostoiévski, no Velho Mundo, era permitido exibir, em romances como Os irmãos Karamázov, a arquitetura polifônica; ao brasileiro Machado cabia apenas a fina ironia de um discurso dúbio. Afinal, a ideia de um mundo polifônico é, no plano monoteísta, a ruína e ameaça a eternidade divina - como menciona o autor Bentinho (em nome do autor Machado), em trecho que veremos em seguida. Para os leitores 
do escritor brasileiro, portanto, era importante que se seguisse, na leitura principal, um texto de aparência monológica, enquanto sob o tapete textual a poeira da polifonia pudesse infiltrar-se, pelas hábeis mãos machadianas, contaminando o aparente texto unicista. Se aqui não há, como na leitura do escritor russo, a clara noção de que a verdade é composta por muitas versões possíveis, cada uma atribuída ao olhar de um sujeito, ao menos em Dom Casmurro é possível depreender o embrião desse conceito polifônico, a ideia de que ninguém nunca está sozinho quando profere um discurso.

O próprio Bento, em suas reflexões sobre a vida, citando palavras de "um velho tenor italiano que [aqui] viveu e morreu" (Cap. VIII), concebe a imagem perfeita da representação do mundo como uma ópera. No nono capítulo, em trecho longamente transcrito abaixo, Bentinho relata uma conversa transformadora que teve com um amigo cantor:

- A vida é uma ópera e uma grande ópera. O tenor e o barítono lutam pelo soprano, em presença do baixo e dos comprimirás, quando não são o soprano e o contralto que lutam pelo tenor, em presença do mesmo baixo e dos mesmos comprimirás. Há coros a numerosos, muitos bailados, e a orquestração é excelente...

\section{$[\cdots]$}

Deus é o poeta. A música é de Satanás, jovem maestro de muito futuro, que aprendeu no conservatório do céu. Rival de Miguel, Raiael e Gabriel, não tolerava a precedência que eles tinham na distribuição dos prêmios. Pode ser também que a música em demasia doce e mística daqueles outros condiscípulos fosse aborrecível ao seu gênio essencialmente trágico. Tramou uma rebelião que foi descoberta a tempo, e ele expulso do conservatório. Tudo se teria passado sem mais nada, se Deus não houvesse escrito um libreto de ópera do qual abrira mão, por entender que tal gênero de recreio era impróprio da sua eternidade. Satanás levou o manuscrito consigo para o inferno. Com o fim de mostrar que valia mais que os outros, e acaso para reconciliar-se com o céu, compôs a partitura, e logo que a acabou foi levá-la ao Padre Eterno.

- Senhor, não desaprendi as lições recebidas, disse-lhe. Aqui tendes a partitura, escutai-a emendai-a, fazei-a executar, e se a achardes digna das alturas, admiti-me com ela a vossos pés...

- Não, retorquiu o Senhor, não quero ouvir nada.

- Mas, Senhor...

- Nada! Nada!

Satanás suplicou ainda, sem melhor fortuna, até que Deus, cansado e cheio de misericórdia, consentiu em que a ópera 
fosse executada, mas fora do céu. Criou um teatro especial, este planeta, e inventou uma companhia inteira, com todas as partes, primárias e comprimárias, coros e bailarinos.

--Ouvi agora alguns ensaios!

--Não, não quero saber de ensaios. Basta-me haver composto o libreto; estou pronto a dividir contigo os direitos de autor. (Cap. IX)

A máxima "a vida é uma ópera", por si só, já traduz com perfeição a ideia da polifonia "orquestrada" teoricamente por Bakhtin, que atribui a Dostoiévski sua criação artística. A ópera é a metáfora audiovisual de um mundo polifônico. No entanto, há na justificativa apresentada ficcionalmente pelo tenor, para a concepção de sua teoria, argumentos que merecem comentário. A parceria entre Deus e Satanás é a perfeita imagem diatópica da composição de um discurso. Não há texto, por mais monológico que se apresente, que não leve em conta a voz de outro - sobretudo o que lhe remete à diferença. Não há argumentação sem contra-argumentação, não há texto sem hipertexto. E a forma como se dá a parceria entre os dois compositores, na história relatada por Bentinho, é um retrato da dialogia intrínseca a todo processo discursivo. Reparemos que Deus havia "escrito um libreto de ópera do qual abrira mão". Em seguida, "Satanás levou o manuscrito consigo para o inferno. [...] compôs a partitura, e logo que a acabou foi levá-la ao Padre Eterno." A apropriação de um texto alheio para a composição autoral é o procedimento formal próprio de todo ato criativo. Afinal,

Um membro de um grupo falante nunca encontra previamente a palavra como uma palavra neutra da língua, isenta de aspirações e avaliações de outros ou despovoada das vozes dos outros. Absolutamente. A palavra, ele a recebe da voz de outro e repleta da voz de outro. (BAKHTIN, 2008, p.232)

A recriação da partitura divina pelo rebelde ex-aluno, a partir das suas "lições recebidas", e a devolução dos escritos ao Pai Eterno para que ele pudesse "emendá-la e fazê-la executar" é a imagem do jogo dialógico que compõe aquela e toda autoria, base conceitual de um universo polifônico. Reforçando o jogo, o autor Bentinho, após narrar o diálogo com o Maestro e as suas ideias sobre o mundo, toma-as para si ao declarar: "Eu, leitor amigo, aceito a teoria do meu velho Marcolini, não só pela verossimilhança, que é muita vez toda a verdade, mas porque a minha vida se casa bem à definição. Cantei um duo tecnicismo, depois um trio, depois um quatro..." (Cap. X) Na sequência, passa a relatar o "duo tecnicismo" que, certa vez, "cantou" com José Dias.

Comecei a andar de um lado para outro, estacando para amparar-me, e andava outra vez e estacava. Vozes confusas 
repetiam o discurso do José Dias:

"Sempre juntos..."

"Em segredinhos..."

"Se eles pegam de namoro..." (Cap. XII)

A denúncia. Assim Bento se refere à primeira participação de José Dias em sua biografia. Sugere ter sido o "amigo" a primeira voz a sussurrar, para a sua mãe e aos quatro ventos, um possível encontro amoroso entre ele e Capitu. O trecho recupera a cena do terceiro capítulo, em que José Dias conversa com D. Gloria e seus familiares sobre a estranha relação entre os jovens: "Não me parece bonito que o nosso Bentinho ande metido nos cantos com a filha do Tartaruga, e esta é a dificuldade, porque se eles pegam de namoro, a senhora terá muito que lutar para separá-los." (Cap. III), diz o pseudomédico. Curiosamente, confessa o autor Bento, nem ele mesmo havia atinado, na época, que haveria amor entre ele e a jovem Capitolina. E questiona-se: "Com que então eu amava Capitu, e Capitu a mim? Realmente, andava cosido às saias dela, mas não me ocorria nada entre nós que fosse deveras secreto." (Cap. XII) O amor por Capitu, mola mestra da autobiografia de Bento e do romance de Machado, foi elaborado em discurso por José Dias, antes mesmo que os amantes tivessem tempo de se envolver em afeto. Foram, então, as palavras de Dias antecipadoras no enamoramento do casal.

A parceria entre Bentinho e José Dias será reforçada adiante, no romance, quando "o agregado" cunhar a célebre frase: "[Os olhos dela] São assim de cigana oblíqua e dissimulada" (Cap. XXV), que será rememorada (e apropriada) por Bento, quando ele estiver prestes a se tornar refém da bela Capitu. Enfeitiçado pela moça, lembrará a "definição que José Dias dera deles, 'olhos de cigana oblíqua e dissimulada"' (Cap. XXXII) e, como Satanás procedeu com a partitura divina, recriará a definição ocular da amada à sua moda: “Olhos de ressaca", dirá. "Traziam não sei que fluido misterioso e enérgico, uma força que arrastava para dentro, como a vaga que se retira da praia, nos dias de ressaca." (idem) $\mathrm{O}$ dueto com Dias se consagra nesse momento, quando os olhos de Bento admitem enxergar o que é visto pelos olhos do outro. A sintonia de olhares (logo, de "pensares") marca o dialogismo que compõe o discurso assinado pelo casmurro autor.

São muitas vozes que compõem a história da vida de Bentinho e, logo, sua subjetividade. Serão, por exemplo, de Prima Justina as considerações mais contundentes que o jovem Bento ouvirá sobre as virtudes de Capitu, mencionada então não mais como a cigana dissimulada de José Dias, mas como uma bela pretendente ao amor. A conversa que teve com a prima sobre a 
futura esposa será um importante passo de Bento até a consumação da relação amorosa:

[Prima Justina] insinuou-me que [Capitu] podia vir a ser uma moça bonita. Eu, que já a achava lindíssima, bradaria que era a mais bela criatura do mundo, se o receio me não fizesse discreto. Entretanto, como prima Justina se metesse a elogiarlhe os modos, a gravidade, os costumes, o trabalhar para os seus, o amor que tinha a minha mãe, tudo isto me acendeu a ponto de elogiá-la também. Quando não era com palavras, era com o gesto de aprovação que dava a cada uma das asserções da outra, e certamente com a felicidade que devia iluminar-me a cara. (Cap. XXII)

No refluxo da relação discursiva, no qual o discurso de um afeta o discurso de outro, Justina também se deixa contaminar pelas palavras do primo, que observa: "Creio que prima Justina achou no espetáculo das sensações alheias uma ressurreição vaga das próprias. Também se goza por influição dos lábios que narram." (Cap. XXII) A aforística conclusão do vigésimo segundo capítulo ratifica as relações que estão emaranhadas ao longo de todo o discurso machadiano (ou "bentiniano"). A "influição" do alheio é um componente genético, e/ou erótico, de todo texto autoral.

Voltemos então a pensar na escrita de Bentinho como um projeto "monológico", já entendendo que o dialogismo e a polifonia estão nas entrelinhas - ou na genética - das suas relações sintático-semânticas. Voltemos a falar em monologia por um motivo muito simples: ela é parte do jogo de cena arquitetado por Machado de Assis. É importante que se pense o texto de Dom Casmurro como projeto subjetivo, como versão de um homem que narra o que viu e ouviu, o que julga a partir desse conhecimento apreendido e o que imagina que houve nos momentos em que nada viu e sobre o qual nem ouviu falar. Deixemos de lado, por ora, os "diálogos" já mencionados: a polifonia intrínseca à voz de Bento e a refração desse discurso diante da mensagem do autor. Afinal, todos sabemos, o romance segue um caminho narrativo rumo ao clímax que o imortalizou: a controvertida relação amorosa entre Bentinho e Capitu, após a suspeita do marido sobre uma suposta traição de sua mulher com o seu melhor amigo Escobar. Há um não-saber autoral que é parte integrante da trama enredada no romance e que precisa ser encenado para se tornar apreensível pelo leitor. O discurso monológico é, nesse contexto, o olhar de um homem limitado ao seu saber subjetivo.

$\mathrm{O}$ artifício do autor secundário, neste romance, portanto, é muito mais que um projeto estético do escritor, é uma necessidade da composição de uma estratégia discursiva. $\mathrm{O}$ autor Bentinho crê naquilo que se projeta diante de seus olhos e, principalmente, em sua mente. Ele atribui à sua versão um status de 
2A ideia da duplicidade discursiva como forma de ironia foi formulada, dentre outros teóricos, por Lukács, que assim se justifica: "O autoreconhecimento, ou seja, a auto-superação da subjetividade, foi chamado de ironia pelos primeiros teóricos do romance, os estetas do primeiro Romantismo. Como constituinte formal da forma romanesca, significa ela uma cisão interna do sujeito normativamente criador em uma subjetividade como interioridade, que faz frente a complexos de poder alheios e empenha-se por impregnar o mundo alheio com os conteúdos de sua aspiração, e uma subjetividade que desvela a abstração e portanto a limitação dos mundos reciprocamente alheios do sujeito e do objeto, que os compreende em seus limites, concebidos como necessidades e condicionamentos de sua existência, e que, mediante esse desvelamento, ainda que mantenha intacta a dualidade do mundo, ao mesmo tempo vislumbra e configura um mundo unitário no condicionamento recíproco dos elementos essencialmente alheios entre si." (LUKÁCS, 2007, pp. 74-75) verdade. Seria simplista dizer que ele é o narrador da dúvida, como muito se diz no campo da pedagogia literária. O que o romance propõe é algo mais complexo que isso. O que se lê é mais a presunção da certeza, contextualizada em um mundo de versões, do que um teorema sobre a dúvida. A diferença pode parecer meramente retórica, mas revela-se substancial quando se pensa na arquitetura dos dois discursos. Representar a dúvida é evidenciar a ambiguidade, enquanto a representação da verdade presumida requer a ocultação (sem a total anulação) de uma voz em detrimento à outra. A dúvida se traduz em imagem visível, a presunção de certeza necessita da palavra escrita para articular o seu jogo irônico, que esconde no texto um subtexto. A narração na primeira pessoa de Bentinho, arranjada pelas mãos de Machado de Assis, é exemplar para se pensar a duplicidade discursiva própria do projeto romanesco.

A monologia, nesse sentido, é o perfeito disfarce do autor primário escondido sob (ou sobre) as palavras do secundário autor, que "assina" o texto de aparência unicista. Acima do autor ficcional, segurando as linhas que o movimentam - metáfora cênica -, há um escritor primário que, através das articulações formais por ele criadas, comunica-se com o leitor. Distanciado do sujeito da enunciação, o primário autor - ardiloso - está livre para questionar, de fora do texto, aquilo que seu personagem narra com convicção. O efeito duplicado é tão sutil que um leitor ingênuo não o perceberá e aceitará, como verdade do autor real e sua obra, uma verdade defendida por um sujeito ficcional ao longo do romance.

Certa vez, em um debate sobre o romance de Machado de Assis promovido pela ABL, uma jovem estudante manifestouse contrária à versão, defendida ali por alguns leitores, de que Capitu pudesse não ter traído Bentinho, ou melhor, de que a traição fosse fruto da imaginação do enciumado narrador. A moça alegava ter provas materiais do "crime" da bela personagem. "Capitu teve um filho de Escobar!", afirmou perante a plateia, segurando uma edição do romance como se fora uma bíblia. E diante da pergunta: "Mas quem diz isso?", proferiu sem hesitar: "Machado de Assis. Está escrito aqui ó!" O autor, se visse tal cena, escondido onde não pudesse ser notado, daria risadas ou aplaudiria o êxito de um romance planejado para dividir e iludir.

O irônico ${ }^{2}$ efeito de duplicidade discursiva, referido por Bakhtin como a refração do discurso do narrador ou do autor ficcional em face ao discurso do autor real, exige do leitor uma perspicácia de observação. Muito se comenta, por exemplo, do longo período em que Dom Casmurro foi lido simplesmente como a história da traição de Capitu, até que os críticos levantassem a hipótese controversa e ampliassem definitivamente o foco da leitura planejada certamente por Machado de Assis. É preciso levantar o tapete discursivo de Bentinho para enxergar 
a "tessitura" do solo engenhosamente construído pelo gênio da literatura brasileira. Refratar o discurso foi, então, a mecânica necessária para que, embora coerente e coeso, o texto de Bentinho pudesse ser questionado e relativizado, para ser reescrito por um atento leitor. A estratégia, diz o teórico russo, consiste no seguinte:

"[...] o autor inclui no seu plano o discurso do outro voltado para as suas próprias intenções. A estilização estiliza o estilo do outro no sentido das próprias metas do autor. O que ela faz é apenas tornar essas metas convencionais. O mesmo ocorre com a narração do narrador, que, refratando em si a idéia do autor, não se desvia de seu caminho direto e se mantém nos tons e entonações que de fato lhe são inerentes. Após penetrar a palavra do outro e nela se instalar, a idéia do autor não entra em choque com a idéia do outro mas a acompanha no sentido que esta assume, fazendo apenas este sentido tornar-se convencional." (BAKHTIN, 2008, p.221)

Enquanto se lê o texto principal, ordenado logicamente por um sujeito da ficção, também se procuram as "intenções" do autor real, suas "metas". Nas entrelinhas, no subtexto, é que se notarão as ideias do autor diante de um saber do outro, o aparente narrador ou o segundo autor. É preciso colher as pistas deixadas pelo escritor nas entranhas do texto narrado para se entender sua mensagem duplicada. Vejamos, por exemplo, um trecho em que Bentinho descreve o comportamento de uma curiosa Capitu, que desejava ter informações detalhadas sobre a conversa de José Dias e a mãe de Bento sobre a ida do moço ao seminário:

Capitu quis que lhe repetisse as respostas todas do agregado, as alterações do gesto e até a pirueta, que apenas lhe contara. Pedia o som das palavras. Era minuciosa e atenta; a narração e o diálogo, tudo parecia remoer consigo. Também se pode dizer que conferia, rotulava e pregava na memória a minha exposição. Esta imagem é porventura melhor que a outra, mas a ótima delas é nenhuma. Capitu era Capitu, isto é, uma criatura mui particular, mais mulher do que eu era homem. Se ainda o não disse, aí fica. Se disse, fica também. Há conceitos que se devem incutir na alma do leitor, à força de repetição. (Cap. XXXI)

O tom assertivo e onisciente com que Bentinho produz sua narração (e descrição) encobre a precariedade de suas informações. As suas afirmações de que Capitu "era minuciosa e atenta", "tudo parecia remoer consigo" e que "conferia, rotulava e pregava na memória a [sua] exposição" não podem ser garantidas por um narrador que, humanizado, está limitado a um saber apreensível. Somente a própria Capitu ou um narrador divinizado, logo distanciado da ação, poderiam confirmar os seus pensamentos e intenções. As impressões de Bentinho, ou o julgamento que faz da amada, ocupam a cena narrativa 
e produzem uma planejada distorção: o "Capitu parece ser" é tomado como um "Capitu é". A opinião do personagem-autor sobre a amada é vociferada como a verdade soberana de sua caracterização. Essa verdade, entretanto, se restringe ao plano refratado da ficção em relação ao plano ideal do autor primário, onde estão as "metas" que ele deposita em sua criação textual.

Há uma senha para se "acessar" o autor real, no entanto, nas brechas que há no discurso do narrador ou do segundo autor, onde estão as pistas que ele deixa para ser revelado como um "outro" no texto de Bentinho, garantindo o efeito irônico ou refratário da obra. No trecho supracitado, quando diz: "Há conceitos que se devem incutir na alma do leitor, à força de repetição", Bento (e, por trás dele, o primário autor) chama à responsabilidade um leitor que pode intervir no discurso. Se há o que se "incutir" no leitor, há provavelmente o que se avaliar como juiz de um processo argumentativo. Se nós, leitores, estamos sendo convencidos por um discurso peremptório, é melhor termos cuidado para considerar os prováveis e improváveis em relação àquilo que nos é apresentado. Essa constatação será a chave para a revelação de que, para além da voz de Bentinho, há um Machado que não se compromete ideologicamente ou axiologicamente com as ideias defendidas por seu personagem.

Repensemos, nesse ponto, o caso da ABL aqui mencionado, no qual uma estudante indignava-se com as dúvidas, de outros leitores, acerca do que afirmava o enunciador do romance. O desempenho "retórico" do autor Bentinho foi de tal sorte convincente, que não permitiu à leitora enxergar Machado de Assis fora de cena, nos bastidores, divertindo-se com a criação de um texto que imprimia um tom absoluto à versão pessoal de um sujeito inventado, logo, que tornava geral (por descuido de leitura) aquilo que era singular. A suposta paternidade de Escobar, por ela mencionada, é um lance de mestre do criador ilusionista, um sofisma. Machado fornece ao seu narrador um argumento contundente para advogar em seu favor: o filho era do outro. Para prová-lo, contudo, não há documentos, impressões de outras personagens, nada. Apenas os olhos de Bentinho testemunham em seu favor:

Nem só os olhos, mas as restantes feições, a cara, o corpo, a pessoa inteira, iam-se apurando com o tempo. Eram como um debuxo primitivo que o artista vai enchendo e colorindo aos poucos, e a figura entra a ver, sorrir, palpitar, falar quase, até que a família pendula o quadro na parede, em memória do que foi e já não pode ser. Aqui podia ser e era. [...]

Escobar vinha assim surgindo da sepultura, do seminário e do Flamengo para se sentar comigo à mesa, receber-me na escada, beijar-me no gabinete de manhã, ou pedir-me à noite a bênção do costume. (Cap. CXXXII) 
Nesse outro trecho, a afirmação de que as "feições" do filho se iam moldando à semelhança do amigo Escobar é, assim como notamos no trecho anterior a esse, narrada como certa e, com desatenção, pode se tornar inquestionável por parte de um leitor que, despercebido, se enlaça ao orador como se estivesse diante de um altar. É preciso entender a estratégica irônica do autor para procurar o avesso do que é tecido na narração. Mais adiante, por exemplo, quando, após longo período de silêncio, Bentinho confessa a Capitu sua desconfiança sobre a paternidade de Ezequiel, a reação da mulher é descrita não por alguém que a vê, mas por outro que acredita penetrar sua alma e, ciente da sua interioridade, desvendar seus mais secretos pensamentos:

Grande foi a estupefação de Capitu, e não menor a indignação que lhe sucedeu, tão naturais ambas que fariam duvidar as primeiras testemunhas de vista do nosso foro. Já ouvi que as há para vários casos, questão de preço; eu não creio, tanto mais que a pessoa que me contou isto acabava de perder uma demanda. Mas, haja ou não testemunhas alugadas, a minha era verdadeira; a própria natureza jurava por si, e eu não queria duvidar dela. Assim que, sem atender à linguagem de Capitu, aos seus gestos, à dor que a retorcia, a cousa nenhuma, repeti as palavras ditas duas vezes com tal resolução que a fizeram afrouxar. (Cap. CXXXVIII)

A "estupefação" e a "indignação" de Capitu pareceram grandes aos olhos de Bentinho, por um lado, mas intimamente ele prefere interpretá-las como meros jogos de cena da mulher, "tão naturais ambas que fariam duvidar as primeiras testemunhas de vista do nosso foro", diz ele. A possessiva primeira pessoa do plural, cuidadosamente encaixada na narração de Bento, mais do que uma majestática pronominalização, busca a cumplicidade do leitor com o que o enunciador defende. $\mathrm{O}$ autor, por trás de sua criatura, restringe-se a esperar que um leitor atento note que em momento algum há uma alusão à traição de Capitu que não venha do próprio Bentinho. Ninguém confirma o comportamento inadequado da mulher amada. Não há qualquer insinuação a respeito da índole duvidosa da moça de olhos expressivos, a não ser a menção de José Dias, o "falso" médico - é bom aqui lembrar -, ao fato de que ela, ainda menina, parecia ter "olhos de cigana oblíqua e dissimulada", outra peçachave na narrativa para desviar os olhos leitores da mensagem machadiana encoberta pelo texto de Bentinho.

$\mathrm{O}$ autor real, escondido para não ser notado, convoca o leitor a descobri-lo na sombra (ou ressuscitá-lo de uma morte impossível). Provocando-o a levantar-se da passiva poltrona receptora para posicionar-se diante do que lê - a partir do questionamento subjetivo diante da verdade defendida pelo autor secundário -, esse autor marca sua presença e garante o sucesso irônico de sua obra: 


\section{ABANE A CABEÇA, LEITOR}

Abane a cabeça leitor; faça todos os gestos de incredulidade. Chegue a deitar fora este livro, se o tédio já o não obrigou a isso antes; tudo é possível. Mas, se o não fez antes e só agora, fio que torne a pegar do livro e que o abra na mesma página, sem crer por isso na veracidade do autor. (Cap. XLV)

Não crer na "veracidade do autor" ficcional é, logicamente, entender o jogo dúbio da autoria romanesca entre o dito e o pretendido. Duvidar do autor secundário é estar pronto para decodificar a ironia que constitui o romance, é aventurar-se por um terreno de mistérios. É preciso escavar o romance de Machado de Assis, para retirar das entranhas o seu fundamento. E, encontrada a ossatura do romance, é necessário estar preparado para conviver com a duplicidade discursiva: dois discursos que duelam por uma existência - qual a verdade da obra?

Mais do que procurar uma única resposta, o leitor deverá convencer-se de que está diante de um texto impresso sob a égide de uma simbologia biunívoca, onde vale a dupla significação. Deverá convencer-se de que "O homem não tem um território interior soberano, está todo e sempre na fronteira, olhando para dentro de si ele olha o outro nos olhos ou com os olhos do outro." (BAKHTIN, 2008, p.323) A apreensão da história de Bentinho, portanto, como discurso enunciado sobre a formação de um indivíduo - dentro da ótica bivalente - deve ser repensada. A sua configuração a partir da premissa de que "as experiências formam o sujeito" é inegável e, por esse motivo, não há que se destituir o livro da condição de romance de formação. Entretanto, na medida em que se reconhecem as intenções ("metas") irônicas do autor primário na composição do texto, e por isso já se sabe que ele quer mais do que narrar uma trajetória de vida, é preciso entender o processo de formação na obra como parte de um jogo autoral.

Entender o percurso de vida de Bentinho, suas experiências e seus aprendizados, é aceitar a composição crível de um

enunciador. É, sobretudo, entendê-lo como um sujeito complexo, formado a partir de vozes alheias, enviesado em sua forma de pensar por conta da doutrinária formação recebida. Só conhecendo a história pregressa de Bentinho, conseguimos aceitá-lo como sujeito autônomo (em relação aos outros personagens e ao autor) e identificar o foco refratado de seu discurso para só então procurar as ideias autorais na sua sombra. A construção do sujeito Bentinho, articulada por um autor que não advoga em seu favor, revelar-se-á - nesse contexto - o processo de formação de um ponto de vista. Um entre tantos, a convocar o olhar do leitor para a cena jurídica: Quem está com a razão? Ou, melhor que isso: Onde está a razão? Ela existe por si só? Entendida a complexidade da trama tecida no texto de Machado de Assis, o 
leitor terá condecorada a sua condição de maturidade. E só com ela poderá perceber que ele é parte integrante do livro. Afinal, Dom Casmurro é um romance de palavras e silêncios. Silêncios que precisam ser preenchidos ou, nas palavras de Drummond, "poemas que esperam ser escritos".

\begin{abstract}
:
Drawing on the concepts of Bakhtin analysis of the novel form, particularly on the polyphonic discourse, the article proposes a reading of the book by Machado de Assis as a novel of formation, which relies on irony to refract the fictional voice built (or formed) in relation to other voices that might question or deconstruct it.
\end{abstract}

Keywords: Dom Casmurro. Irony. Novel of formation. Dialogism and polyphony.

\title{
Referências e consultas bibliográficas
}

ADORNO, Theodor W. Notas de literatura I. São Paulo: Duas Cidades. Ed.34, 2003.

ASSIS, J. M. Machado de. Dom Casmurro. São Paulo: Ática, $12^{\mathrm{a}}$ ed., 1981.

AUERBACH, Erich. Ensaios de literatura ocidental. Trad. Samuel Titan Jr et ali. Ed. 34: São Paulo, 2007.

AUERBACH, E. Mimesis. (Tradutor não mencionado). Ed. Perspectiva: São Paulo, $5^{\mathrm{a}}$ ed., 1976

BAKHTIN, Mikhail. Problemas da poética de Dostoievski. Trad. Paulo Bezerra. Ed. Forense Universitária: Rio, $4^{\mathrm{a}}$ ed., 2008.

BAKHTIN, M. Questões de literatura e estética. Trad. Aurora Bernardini et ali. Hucitec: São Paulo, 1988.

BAKHTIN, M. Estética da criação verbal. Trad. Paulo Bezerra, Martins Fontes: São Paulo, 2003.

BENJAMIN, Walter. Magia e Técnica, Arte e Política: ensaios sobre literatura e história da cultura. Trad. Sergio Paulo Rouanet. São Paulo: Brasiliense, 1994. (obras escolhidas; vol.I)

BEZERRA, Paulo . Dialogismo e polifonia em Esaú e Jacó. In: Carlos Alberto Faraco, Cristovão Tezza e Gilberto de Castro. (Org.). Vinte ensaios sobre Milhail Bakhtin. Petrópoilis: Editora Vozes, 2006, v. , p. 38-53.

FOSTER, Edward M. Aspectos do romance. Trad. Sergio Alcides. Ed. Globo: Porto Alegre, 2005.

FOUCAULT, Michel. O que é um autor? 3. ed. s.l.: Veja / Passagens, 1992, p. 29-87.

FRYE, N. Anatomia da crítica. Trad. Péricles E. S. Ramos. Cultrix: São Paulo, 1973. 
HEGEL, Georg W. F. "A forma de arte românica", in Cursos de estética, v. II. Trad. Marco Aurélio Werle e Oliver Tolle. EDUSP: São Paulo, 2000.

JAMES, Henry. A arte do romance. Trad. de Marcelo Pen. Ed. Globo: São Paulo, 2003.

LAJOLO, Marisa. Do mundo da leitura para a leitura do mundo. $6^{\mathrm{a}}$ ed. São Paulo: Ática, 2000.

LUKÁCS, Georg. A teoria do romance. Trad. José Marcos M de Macedo. Ed. 34, S.P., 2000.

LUKÁCS, G. "A fisionomia intelectual dos personagens artísticos", in Marxismo e teoria da literatura. Trad. Carlos Nelson Coutinho, Civilização Brasileira, Rio, 1968.

LUKÁCS, G. "Narrar ou descrever", in Ensaios sobre literatura. Trad. Leandro Konder Civilização Brasileira, Rio, 2ª Ed., 1968. 